\title{
Medication Related Osteonecrosis of the Jaws
}

\author{
Semih Özbayrak' ORCID: 0000-0002-8748-0101 \\ Özlem Okumuşš ${ }^{1 *}$ ORCID: 0000-0002-5590-2357
}

${ }^{1}$ Altınbaş University, Faculty of Dentistry, Department of Oral and Maxillofacial Radiology, Istanbul, Turkey.

Submitted: November 15, 2019; Accepted: December 27, 2019

\begin{abstract}
Medication-related osteonecrosis of the jaw (MRONJ) is a severe adverse drug reaction, including of bone destruction in the jaws. Osteonecrosis of the jaws can be caused by two pharmacological agents: antiresorptive (including bisphosphonates (BPs) and receptor activator of nuclear factor kappa-B ligand [RANK-L] inhibitors) and antiangiogenic. Among the drugs associated with the development of MRONJ, BPs are the most widely used for a wide variety of clinical indications. Bisphosphonates are used in bone metabolism-related diseases such as Paget's disease, fibrous dysplasia, osteogenesis imperfecta, but mainly in lung, prostate, breast carcinomas, multiple myeloma and osteoporosis. The effect of the drug depends on the dose and duration of administration. Epidemiological studies showed that long-term use of these drugs may increase the risk of MRONJ development. The purpose of this review is to define the current information about MRONJ, the management strategies and preventive measures.
\end{abstract}

Keywords: Bisphosphonate; drug therapy; osteochemonecrosis; osteonecrosis of the jaw

Address of Correspondence: Özlem OKUMUŞ-ozlem.okumus@altinbas.edu.tr Tel: +90(212)7094528. Department of Oral and Maxillofacial Radiology and Oral Medicine Clinic, Faculty of Dentistry, Altınbaş University, Zuhuratbaba, Incirli Cd., 34147, Bakırköy, Istanbul, Turkey

\section{Introduction}

Medication-related osteonecrosis of the jaw (MRONJ) can occur after exposure to antiresorptive agents including bisphosphonates or denosumab, or angiogenesis inhibitors to avoid bone complications (Khan et al., 2015).

MRONJ is more common among patients receiving high cumulative doses of bisphosphonates or denosumab than in patients receiving lower doses (de Boissieu et al., 2017; Khan et al., 2017). MRONJ was first reported in 2003 by Marx who reported 36 patients have a history of treatment with bisphosphonates and painful bone exposure in the mandible and maxilla (Marx, 2003). After establishing an relationship 
between MRONJ and bisphosphonate treatment, cases related to denosumab treatment began to emerge in 2010 (Aghaloo et al., 2010; Taylor et al., 2010).

The pathogenesis of MRONJ may be multifactorial and have an association between local trauma/infection and reduced bone turnover after exposure to antiresorptive agents (Nicolatou-Galitis et al., 2019).

Furthermore MRONJ is also related with anticancer agents, including angiogenesis inhibitors, classic chemotherapy agents, tyrosine kinase inhibitors (TKIs), immunotherapeutic agents, and inhibitors of mammalian target of rapamycin (Nicolatou-Galitis et al., 2019).

The purpose of this review is to define the current information about MRONJ, the management strategies and preventive measures.

\section{Molecular Mechanisms Regarding Osteochemonecrosis}

The anticancer agents used in conventional treatment are not selective for tumor cells and other tissues (Greish, 2007). Therefore, all chemotherapeutic agents have side effects on normal tissues and organs (Leaf, 2004). To understand MRONJ physiopathology, the molecular mechanisms that are responsible for bone formation and remodeling in this process should be known.

The capillaries consisting of arterioles and venules have a regular and functional structure (Jain, 2003). Tumor vessels are generally composed of endothelial cells that are unordered, damaged and have wide lumens and in particular have impaired receptor function against angiotensin II, vasoactive mediators (Hashizume et al., 2000; Yuan et al., 1995). In addition, because of increased production of vascular permeability enhancing factors such as bradykinin, nitric oxide, vascular growth factors and prostaglandins, the transition of macromolecular drugs to tumor tissue is easier compared to normal tissues (Eskiizmir et al., 2017; Wu et al., 1998).

All these factors increase the passage through the tumor capillary and cause selective delivery of nanosized macromolecular drugs to tumor tissues (Alberto et al., 2001; Kopecek et al., 2001). In addition, low lymphatic fluid flow in tumor tissue increases prolonged effect of the drug in tumor tissue. This effect is called enhanced permeability and retention effect (EPR) (Matsumura and Maeda, 1986).

Because of the abnormal structure and function of blood and lymph vessels around the tumor, an increase in fluid pressure between tissues is observed (Fukumura and Jain, 2007). As the selectivity of the tumor vessels decreases, permeability increases and hypoxia and acidosis occur in the tumors due to their abnormal metabolic environment (Harris, 2002; Tatum et al., 2006). Hypovascular regions are formed within the tissue due to unstable development of vessels and excessive proliferation of tumor cells. Chronic hypoxia is also seen in areas that are far from the blood vessels. Because of the lactic and carbonic acids formed as a result of anaerobic glycolysis, $\mathrm{pH}$ of the tumor environment is very low (Fukumura and Jain, 2007). Oxygen pressure and $\mathrm{pH}$ values affect tumor growth, metabolism and responses to various treatments. These two properties increase the effect of angiogenic factors and cause the tumor growth and metastasis (Fukumura and Jain, 2007). 
The main purpose of cancer treatment is to destroy the cancer cell without affecting normal tissues. This can only be achieved by selectively targeting the cancer cell. The features in tumor targeting; increasing the localization of the drug in the tumor by active or passive targeting, decreasing the localization in untargeted cells, minimizing drug leakage from the transition regions, preserving the drug from disintegration, keeping the drug in the targeted area for the certain period of time, facilitating the intracellular uptake and biocompatible and biodegradable of the delivery system components (Lammers et al., 2008).

The conventional, biotechnological and gene-based drugs can be selectively transported to specific areas of the body such as organs, tissues and cells by targeting drugs (Erdoğan M. A, 2019). Passive targeting is the natural targeting of the carrier after intravenous injection. Active targeting is magnetic targeting, ultrasonic targeting, and ligand-receptor mediated targeting (Kaş and Eldem, 2002).

Oncogenic mutations targeting signaling pathways and signaling proteins that control the proliferation and/or survival functions in normal cells are common. Changes in signal transduction eliminate the control of cell proliferation and/or survival functions. Therefore, the oncogenic signal transduction plays an important role in the invasion/metastasis process on tumor development. Protein kinases enable protein phosphorylation/activation during signal transduction. Protein kinases are divided into two main groups: membrane located and cytoplasmic located. Protein kinases located in the membrane are called receptor tyrosine kinases (RTK). RTKs contain the tyrosine kinase domain, responsible for activation, in the cytoplasmic portions. These receptors become active after binding with growth factors and interact with target proteins in the cytoplasm to perform signal transduction (Doğan and Güç, 2004; Fizazi et al., 2010).

The signal transduction is reversible and RTK mediated transmission is controlled under physiological conditions. In the carcinogenesis process, the continuous and uncontrolled RTK activity is observed. Cytoplasmic protein kinases include tyrosine kinase inhibitor such as Src, Abl, focal adhesion kinase (FAK), janus family kinase (JAK) proteins. Similar to membrane tyrosine kinases, the continuous and uncontrolled activation of cytoplasmic tyrosine kinases and oncogenic signal transduction accelerate malignant properties such as transformation, tumor growth, motility, invasion, and angiogenesis. Mutations leading to continuous activation of protein kinases and over-expression of protein kinases can lead to oncogenic transformation (Doğan and Güç, 2004; Fizazi et al., 2010).

The inhibition of RTK signaling is important in cancer treatment. Two different types of compounds are used to inhibit RTK signaling. The first is tyrosine kinase inhibition (TKI) with small molecular weight agents and the other is monoclonal antibodies (mAb). Although RTK signal is inhibited in both ways, there are also different target epitopes (the region on antigen molecule that bind specific receptors on the antibody or sensitive lymphocyte, which determines the specificity of antibody or lymphocyte) and activation mechanisms. TKIs bind competitively to the ATP binding site in the catalytic part of the receptor and inhibit both autophosphorylation and intracellular signal transduction. These agents can be displaced between plasma membranes and interact with cytoplasmic fragments of cell surface receptors and intracellular signaling molecules. mAbs can only act on the molecules expressed or secreted on the cell surface. They do not have the ability to pass through the cell membrane (Macfarlane and Chi, 2010). 
Monoclonal antibodies are the most widely accepted and approved therapy in the cancer immunotherapy methods (Waldmann, 2003). Nowadays, the main antibodies produced as drugs are monoclonal antibodies such as trastuzumab, cetuximab, bevacizumab, alemtuzumab, rituximab. They target mainly breast cancer, colon cancer and various blood cancers. They target cancer-promoting growth factors such as vascular endothelial growth factor (VEGF), epidermal growth factor receptor (EGFR), human epidermal growth factor receptor 2 (HER2), or antigens specifically produced in cancer cells such as CD52 and CD20. Ipilimumab prevents the immune system inhibition by blocking the cytotoxic T lymphocyte antigen -4 (CTLA-4) antigen (Hodi et al., 2010; Hurwitz et al., 2004; Keating et al., 2002; Reff at al, 1994; Waldmann, 2003).

The epidermal growth factor receptor (EGFR) is an overexpressed tyrosine kinase receptor in many types of cancer such as breast, ovary, colorectal and head and neck cancer. It is involved in cancer cell proliferation, tumor growth, angiogenesis and metastasis. Cetuximab is a monoclonal antibody targeting EGF and clinically approved for cancer immunotherapy (Hamid, 2004).

Human epidermal growth factor receptor 2 (HER2) is a tyrosine kinase receptor and growth factor and belongs to the same family as EGFR. HER-2 is expressed as a growth factor abnormally high in 25-30\% of breast cancers. In breast cancer with increased HER-2 expression, the disease is more aggressive and shorter survival is observed in women (Press et al., 1993; Ravdin and Chamness, 1995; Seshadri et al., 1993). Trastuzumab is an IgG1 isotype monoclonal antibody that binds to HER-2. It inhibits the signaling pathways in cancer cells by binding to HER-2 (Slamon et al., 2001).

CD20 is a differentiation a ntigen found in normal and malignant B cells but not in precursor B cells (Chamuleau et al., 2010). Rituximab is an IgG1 isotype chimeric monoclonal antibody directed against the CD20 antigen. This antibody has been shown to be effective in the treatment of B cell non-Hodgkin lymphomas (Maloney et al., 1997).

CD52 is a differentiation antigen found in all lymphocytes and has been associated with some lymphomas (Buggins et al., 2002; Piccaluga et al., 2007; Ratzinger et al., 2003). Alemtuzumab is an lgG1 isotype monoclonal antibody directed against the CD52 and clinically approved for the treatment of B cell leukemia (Riechmann et al., 1988).

CTLA-4 (cytotoxic T lymphocyte antigen4) is expressed in the membrane of helper T cells and involved in transmitting inhibitory signals to T cells. Therefore, it attempts to prevent the inhibition and suppression of the immune system. It has provided high survival rates in advanced melanoma patients compared to normal treatment with ipilumumab (Beck et al., 2006).

One of the most important factors in the formation of new vessels is VEGF. Serum VEGF levels were increased in the majority of patients with metastatic cancer (Kraft et al., 1999). Bevacizumab is an lgG1 isotype monoclonal antibody that targets VEGF. This antibody inhibits angiogenesis by binding to VEGF (Los et al., 2007). Bevacizumab is approved for clinical use in metastatic colorectal cancer and non-small cell lung cancer, since it significantly improves survival rate when combined with chemotherapy in patients with metastatic colorectal cancer (Hurwitz et al., 2004). 
There are more monoclonal antibodies used in the treatment of cancer. There are various side effects such as fatigue, fever, headache and muscle pain, difficulty in breathing, hypertension, hypothyroidism, dry skin and coloration, hair color change, mild erythema and hyperkeratosis, symmetrical painful, erythematous and swollen areas and petechial hemorrhages, hyperglycemia, hyperlipidemia, stomatitis and pneumonia, hepatotoxicity, arrhythmias (Elloumi et al., 2012; Şakalar et al., 2013).

One of the proteins controlling physiological and pathological bone resorption is the receptor activator nuclear kappa B (RANK) that is found in osteoclasts and cause bone destruction by stimulated with RANK ligand (RANKL). Bone mass is determined by the coexistence of osteoblasts and osteoclasts. Denosumab has a negative effect on osteoblast formation and function by decreasing the effect of RANK molecules on osteoclasts in bone metastases of prostate cancer (Demirkazık and Özal, 2010; Henry et al., 2009; Rosella et al., 2016). Unlike bisphosphonates, it is not nephrotoxic, therefore it is thought to be an alternative to zoledronic acid in patients with bone metastases with renal dysfunction. Recent studies of breast and prostate cancer with bone metastases have shown superiority to zoledronic acid in preventing and delaying skeletal-related events. It has also been shown to reduce metastatic bone pain, like zoledronate (Henry et al., 2009). Also the mucosal and bone changes of jaws may be occurred by this group medication, but as an important feature, frequent improvements and frequent recurrences are common (Özbayrak and Pekiner, 2016).

\section{Bisphosphonate Related Osteonecrosis of the Jaw}

Bisphosphonates are structural anologues of endogenous non-metabolized inorganic pyrophosphonates that regulate the bone mineralization and are drugs that inhibit osteoclastic function. In the healthy bone, osteoblastic bone formation occurs by osteoblast migration to the osteoclastic resorption site (remodeling mechanism). These two functions are essential for the repair of physiological disturbances. Bisphosphonate group drugs easily bind to hydroxyapatite crystals at remodeling sites. They are released from this area and absorbed by osteoclasts. The bisphosphonate inhibits the synthesis of farnesyldiphosphonate, a key enzyme of the mevalonate pathway that produces cholesterol within the cell, so the surface properties required for osteoclast to bone resorption. Therefore, the osteoclastic activity and new bone formation is suppressed due to this. This group of drugs also delays the wound healing and tissue repair by inhibiting vascular formation with its antiangiogenic properties (Dumlu et al., 2011; Pekiner, 2014).

High doses of bisphosphonates are used to prevent tumor invasion by causing cytotoxic effect on osteoblasts, apoptosis of tumoral cells. While the half-life of bisphosphonates in the bloodstream is 30-120 minutes, the unmetabolized bisphosphonate in the bone can remain for up to 10 years. It is known from the in vitro studies that bisphosphonates disrupt endothelial cell proliferation, adhesion and migration. When the active substance reaches a sufficient concentration in the bone, they also create toxic effects on the soft tissue covering the bone surface and inhibit the epithelial cell proliferation (Özbayrak and Pekiner, 2016).

The effect of the drug depends on the dose and duration of administration. Since bisphosphonates increase bone mineral density, they are widely used by oral administration for the prophylaxis of bone 
fractures related with osteoporosis. $10 \mathrm{mg} /$ day per oral administration increases the probability necrosis within 4 years. Once a month intravenous administration used, the probability of necrosis increases within 2 years (Özbayrak and Pekiner, 2016).

Bisphosphonates are used in bone metabolism-related diseases such as Paget's disease, fibrous dysplasia, osteogenesis imperfecta, ankylosing spondylitis, but mainly in lung, prostate, breast carcinomas, multiple myeloma and other malign tumors (Özbayrak, 2017).

Bisphosphonate used before the eruption period may cause dental retention due to the deterioration of osteoclastic activity in the eruption pathway. Gastrointestinal intolerance and esophageal ulcers may be occured in oral administration of the preparation, influenza-like symptoms such as fever, myalgia, arthralgia, nausea, vomiting, as well as uveitis-scleritis and renal failure may be occured with i.v. administration (Özbayrak and Pekiner, 2016).

Bisphosphonate group drugs are divided into two main subgroups;

Nitrogen-containing bisphosphonates (aminobiphosphonates); there are long R2 chains containing nitrogen. Their effects are 100-2000 times stronger than those that do not contain nitrogen (alendronate, risedronate, pamidronate, ibandronate, zoledronic acid) (Marx, 2011).

Nitrogen-free bisphosphonates; known as first generation bisphosphonates. R2 chains are short. When they reach bone tissue, they are captured by osteoclasts and converted into toxic analogs of adenine triphosphate in the cell and show their effect by this way. They are metabolised very quickly in the body (etidronate, tiludronate, clodronate) (Marx, 2011).

The chemical difference prevents the bisphosphonates from hydrolyzing in acidic environment and allows them to remain in the tissues for longer. The carbon at the center of the bisphosphonates binds to hydroxyapatite in bone, and the peripheral chains (R1, R2) are variable. The major chain responsible for the antiresorptive mechanism is R2 chain, the nitrogen group (Özbayrak and Pekiner, 2016).

Due to the rapid metabolic functioning and high turnover of the jaw bones and the deterioration of this cycle related the effect of the drug, the bone/mucosal necrosis occurs to a large extent in the jaws. The remodeling rate of the alveolar bone is 10 times higher than the femur and tibia. Osteonecrosis is common more frequently in the jaw bones because the jaw bones are frequently exposed trauma such as prosthesis, so the integrity of the fine periosteum and mucosa easily deteriorates and allows microorganisms to settle (Marx, 2011). 1/3 of the cases occur in the maxilla and 2/3 of the cases occur in the mandible. Up to $5 \%$ of cases can involve both jaws. In addition, while $25 \%$ of the cases occur spontaneously, $75 \%$ have related with a dental procedure (Özbayrak and Pekiner, 2016).

A wide variety of potential risk factors for the development of osteonecrosis is divided into two, locally and systemically (Nicolatou-Galitis et al., 2019) (Table 1).

Osteonecrosis lesions are clinically asymptomatic or or in some cases blunt pain but usually severe pain (70\%) is observed. Paresthesia may also develop according to localization of lesion (Figure 1-3). In addition, 
osteomyelitis, sequestration, trismus, halitosis, extra/intraoral fistula, anesthesia, actinomyces and many other microorganism-related infections, mobility of adjacent teeth may be detected (Font et al., 2008).

Table 1. Risk factors for the development of osteonecrosis of the jaw

\begin{tabular}{|l|l|}
\hline Local risk factors & Systemic risk factors \\
\hline Tooth extraction & Use of corticosteroids \\
\hline Surgical procedures & Immunosuppressive therapy \\
\hline Subgingival curettage & Anemia \\
\hline ill-fitting dentures & Diabetes mellitus \\
\hline Dental / periodontal infection & Smoking \\
\hline Irritation of the apical periodontium & \\
\hline Poor oral hygiene & \\
\hline
\end{tabular}

Figure 1. (a) Clinical and radiological view of bone necrosis around the teeth 27 after 10 months administration of i.v zoledronic acid in breast cancer (b) Diffuse bone necrosis in the clinical and radiological image of the same patient resembling periodontal abscess in teeth region 34-35.
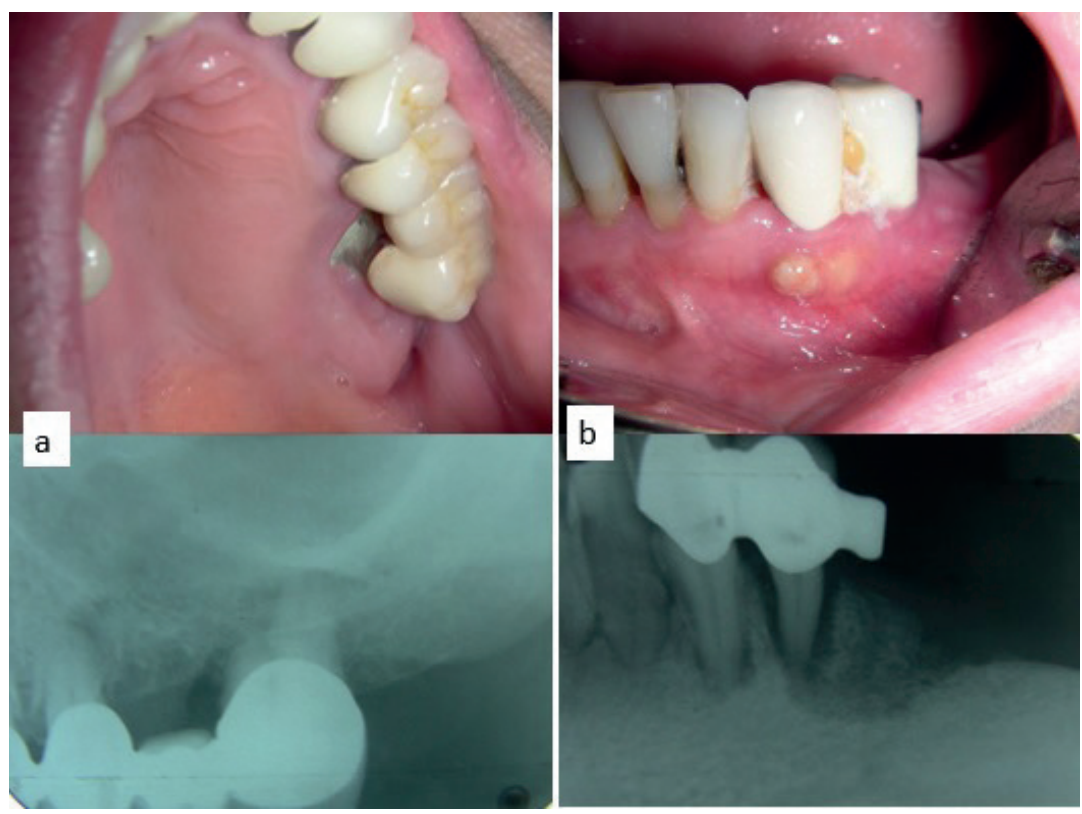
Figure 2. The oro-nasal communication with perforation of the soft tissue and large necrotic area of the palatinal bone in a patient using zoledronic acid for breast cancer.

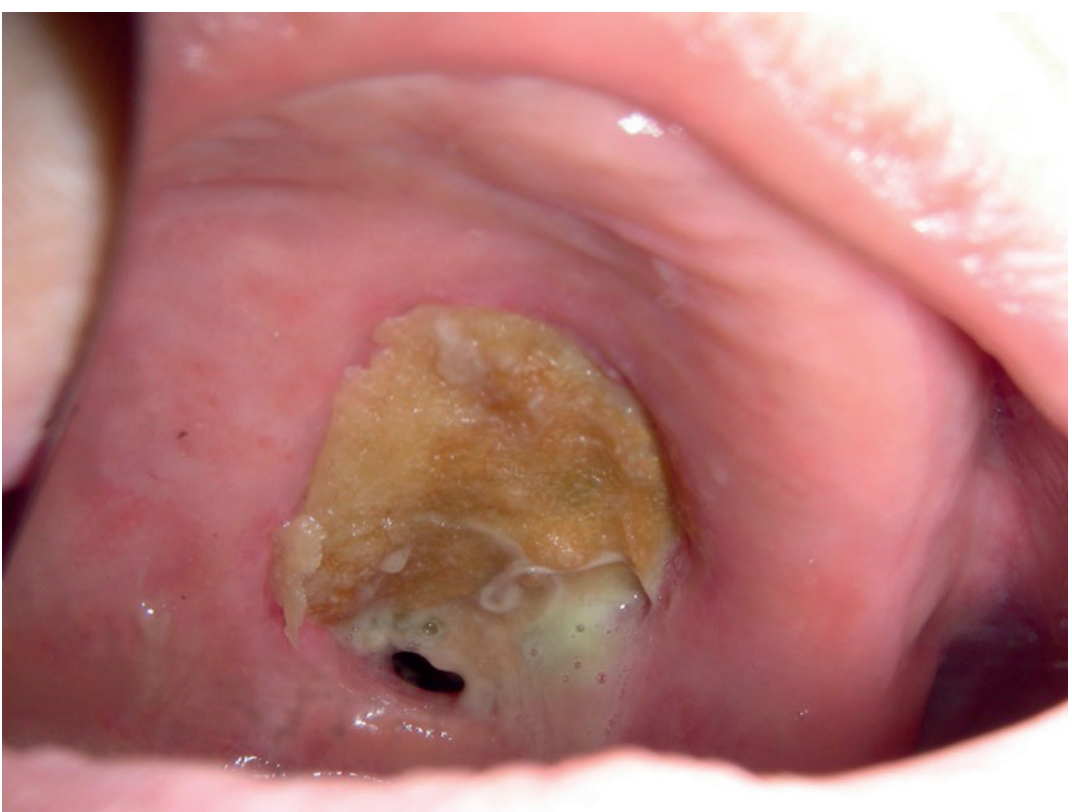

Figure 3. The large sequester due to i.v. zoledronic acid administration once a month for 2 years in the breast cancer.

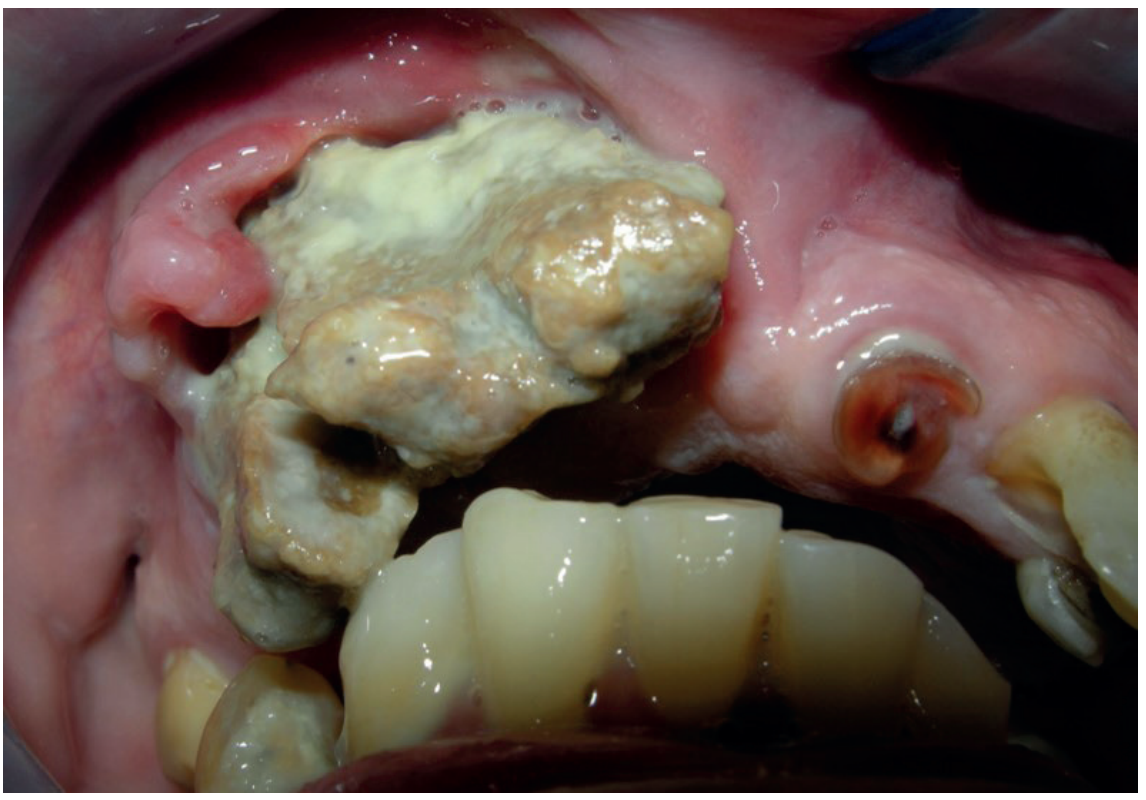

Radiological findings are not initially specific. Initially, the periodontal ligament space widening, as the lesion progresses large radiolucent areas, spontaneous fracture, increase in bone mineral density, change in bone formation, erosion in cortical bone, new bone formation in periostal bone and sequester may be observed (Özbayrak and Pekiner, 2016) (Figure 4 and 5). 
Figure 4. The necrotic bone due to zoledronic acid administration in the multiple myelom and the sequester separated clearly from intact bone on OPTG and axial CT scan.
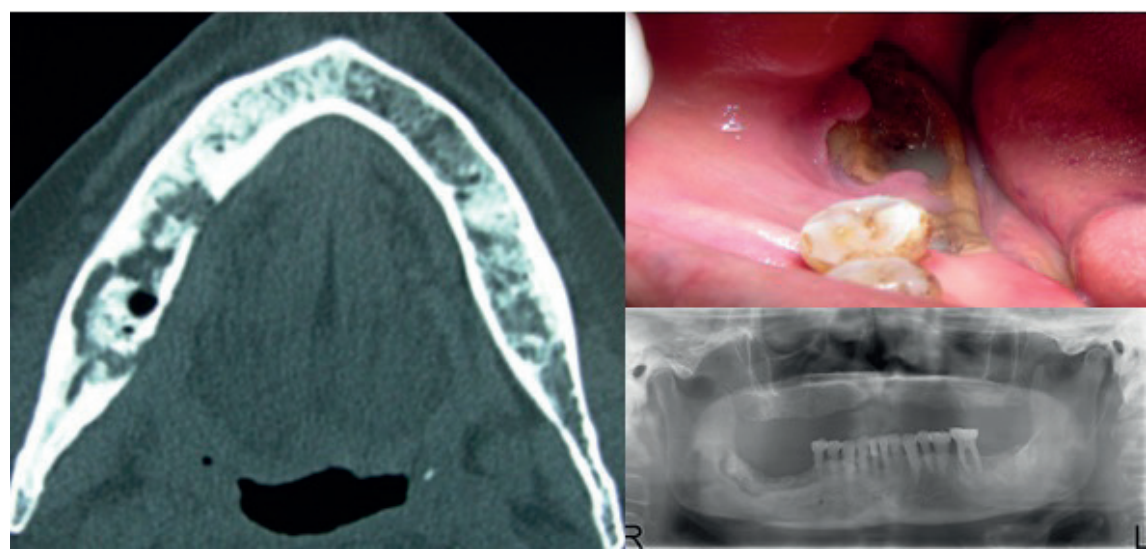

Figure 5. (a)The necrotic bone related i.v. zoledronic acid administration in patient with breast cancer. (b) Extraoral sinus tract of infection (c) Multiple involvement on scintigraphic examination with Tc-99.

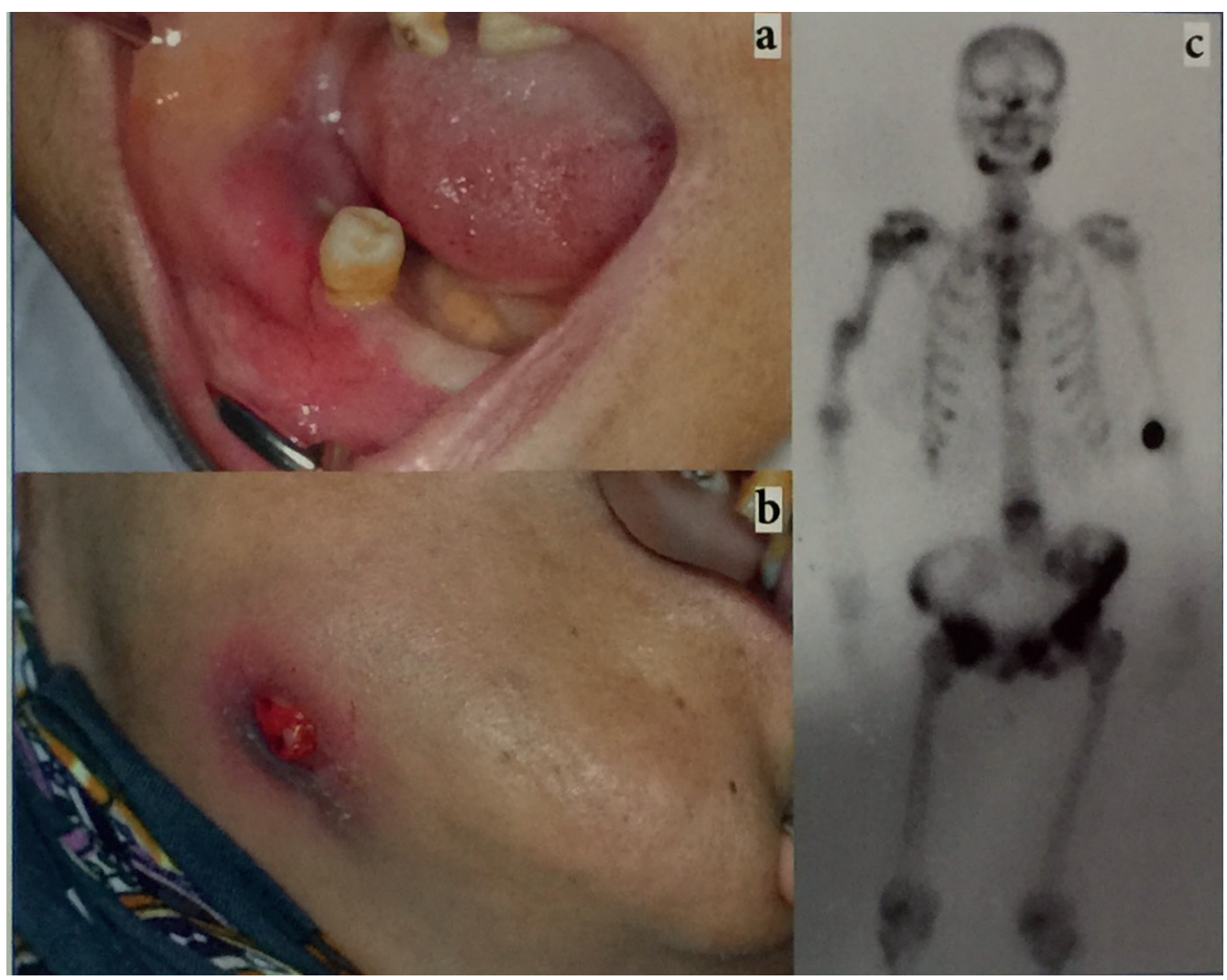


In patients with bisphosphonates related osteonecrosis, first of all, medical treatment should be started in order to relieve the pain, control the infection in soft and hard tissues and stop the progression of the disease. Antibiotics (penicillin, second generation cephalosporins, macrolides), chlorhexidine mouthwashes as antiseptically should be used to prevent the development of secondary infection and the wound should be washed regularly with serum. The general approach should be to wait for the spontaneous sequestration of the necrotic bone with antibiotic protection without the mechanical intervention (Doğan et al., 2009).

Antifungal treatment should be performed when necessary. Dental treatments such as tooth extraction, surgical procedures and soft tissue interventions including curettage should be avoided. If surgical procedures are required, the vasoconstrictor-free anesthetic should be used and the serum carboxyterminal telopeptide (CTX), a bone turn-over marker, should be checked to determine the risk of osteonecrosis. If the serum CTX value is $150 \mathrm{pg} / \mathrm{ml}$ or more, there is a minimal risk of osteonecrosis, levels of $100-150 \mathrm{pg} / \mathrm{ml}$ indicate a moderate risk, while levels of less than $100 \mathrm{pg} / \mathrm{ml}$ a high risk. It is necessary to contact the oncologist to discontinue the bisphosphonate (drug holiday) at least three months before the surgical procedure. At the first examination and three months later it is necessary to measure the CTX. Values lower than $150 \mathrm{pg} / \mathrm{ml}$ would advise against surgical procedures and an interruption prolonged for another three months (Doğan et al., 2009). However, recent studies have suggested that this marker is not very safe.

\section{Approach to Bisphosphonate Related Osteonecrosis}

The treatment of osteonecrosis related bisphosphonate-derived drugs depends on the amount of the necrosis bone, whether the infection reaches the cortical part of the bone or the medulla layer. In oncologic patients, whether the systemic condition is suitable for the operation and the disease staging is also important (Özbayrak and Pekiner, 2016).

Generally, the small exposed areas can be removed with bone file after oral mouthwash and antibiotic use, and then the soft tissue can be expected to be healed. In total osteonecrosis of the alveolar process, only the resection of the alveolar process, called marginal mandibulectomy/maxillectomy or alveolectomy, may be sufficient. In marginal resections, the necrosis bone is removed until reaches the underlying bleeding living medullar bone and antibiotic treatment is applied. In determining this border, it is advantageous to distinguish the accumulation of pre-operative systemic tetracycline in the intact part of the vessel using the optic device that uses blue light with a $400-460 \mathrm{~nm}$ wavelength in order to prevent unnecessary tissue loss (Figure 6). Partial mandibulectomy is performed for infections affecting the entire segment of the mandible. Following the resection of the jaw, a reconstruction plate is placed at the defect to maintain mandible function (Özbayrak and Pekiner, 2016). 
Figure 6. The osteonecrosis in patient using zoledronic acid with the diagnosis of prostate cancer and pelvic metastasis. The view of sequester via the optic device that uses blue light with 400-460 nm wavelength (Velscope) and intraoral view (The blue-green color of the light gradually decreases in cancerous tissues).

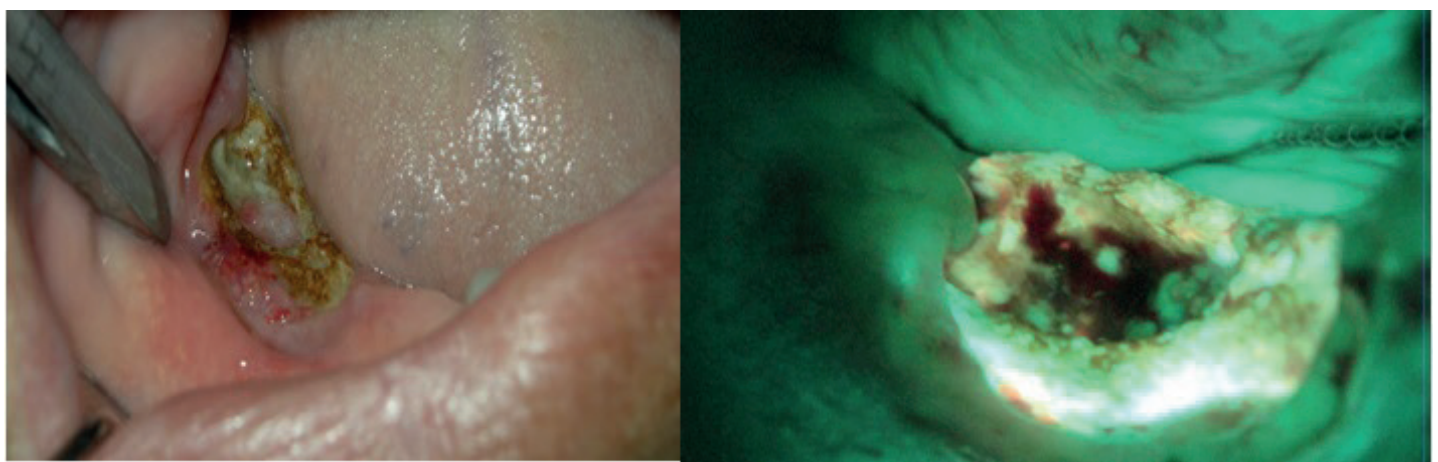

Especially in advanced oncologic patients, the operation may be contraindicated and it would be appropriate to approach with local precautions. In general, after the infection is suppressed by using double antibiotic pressure and chlorhexidine mouthwash, the mucosa can be healed with a conservative approach by removing the part of the necrotic bone seen in the mouth. Osteo-antral fistula may develop especially in large osteonecrosis involving maxillary sinus floor. In this case, the maxillary sinus should be isolated from the oral environment using a palatal plate (Özbayrak and Pekiner, 2016) (Figure 7).

Figure 7. The oro-antral perforation on the necrotic area extending to the zygomatic crista in a patient using zoledronic acid for breast cancer.

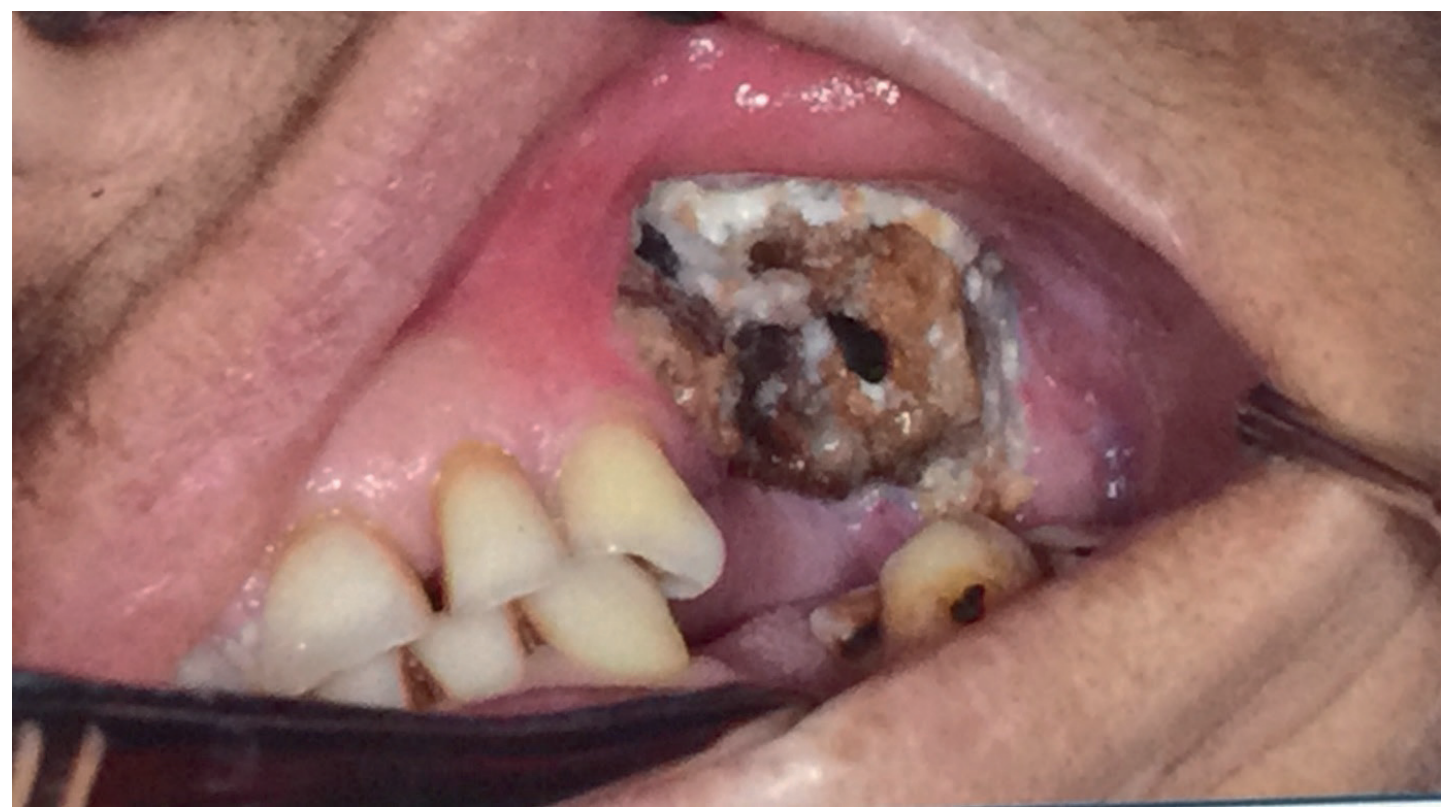


For patients receiving antiresorptive therapy for longer than 4 years, the position paper 2014 of the American Association of Oral and Maxillofacial Surgeons (AAOMS) recommended discontinuation of antiresorptive treatment approximately 2 months prior to invasive dental treatment with preoperative consultation (Ruggiero et al., 2014).

The position paper 2017 of the Japanese Allied Committee on osteonecrosis of the jaw proposes that without discontinuation of bisphosphonates dentists can begin conservative dental treatment. According to their proposal, invasive dental procedures such as tooth extraction can be conducted without discontinuation of antiresorptive treatment following extensive infection control, administration of antibacterial agents in advance and restriction of surgical area (Yoneda et al., 2017). However, no consensus has yet been reached regarding whether bisphosphonates drug holiday before invasive dental treatment is necessary for prevention of MRONJ (Yoneda et al., 2017).

\section{Conclusion}

- Good cooperation among physicians, dentists, oncologists, oral and maxillofacial surgens and other healthcare professionals is required to reduce the risk of MRONJ.

- It is important for dentists to be aware of the patients at the risk of this condition.

- The patients should always be carefully examined by a dentist prior to the start of biphosphonates or denosumab or other anticancer agents to remove any focal infection or risk factors.

- For the patients at the risk of this condition, infection control before invasive dental treatments reduces or prevents the occurrence of MRONJ.

\section{Conflict of interests}

The authors declare no conflict of interest.

\section{References}

Aghaloo, T. L., Felsenfeld, A. L., Tetradis, S. (2010). Osteonecrosis of the jaw in a patient on denosumab. J Oral Maxillofac Surg, 68, 959-963.

Alberto, A., Gabizon, M. D. (2001). Pegylated liposomal doxorubicin: metamorphosis of an old drug into a new form of chemotherapy. Cancer Invest, 19, 424.

Beck, K. E., Blansfield, J. A., Tran, K. Q., Feldman, A. L., Hughes, M. S., Royal, R. E., Kammula, U. S., Topalian, S. L., Sherry, R. M., Kleiner, D., Quezado, M., Lowy, I., Yellin, M., Rosenberg, S. A., Yang, J. C. (2006). Enterocolitis in patients with cancer after antibody blockade of cytotoxic T lymphocyte-associated antigen 4. J Clin Oncol, 24, 283-289. 
Buggins, A. G., Mufti, G. J., Salisbury, J., Codd, J., Westwood, N., Arno, M., Fishlock, K., Pagliuca, A., Devereux, S. (2002). Peripheral blood but not tissue dendritic cells express CD52 and are depleted by treatment with alemtuzumab. Blood, 100, 1715-1720.

Chamuleau, M. E., van de Loosdrecht, A. A., Huijgens, P. C. (2010). Monoclonal antibody therapy in haematological malignancies. Curr Clin Pharmacol, 5,148-159.

de Boissieu, P., Kanagaratnam, L., Mahmoudi, R., Morel, A., Drame, M., Trenque, T. (2017). Adjudication of osteonecrosis of the jaw in phase III randomized controlled trials of denosumab: a systematic review. Eur J Clin Pharmacol, 73, 517- 523.

Demirkazık, A., Özal, G. (2010). Prostat kanserinde hedefe yönelik tedavinin yeri. Üroonkoloji Bülteni, 2, 64-68.

Doğan, L. A., Güç, D. (2004). Sinyal iletimi mekanizmaları ve kanser. Hacettepe Tıp Dergisi, 35, 34-42.

Doğan, Ö. O., Kurtuluş, B., Çevik, P. (2009). Bifosfonat kullanan hastalarda oral cerrahi uygulamalarda karşılaşılabilecek sorunlar ve tedavisi. Istanbul Univ Dishekim Fak Derg, 43, 113-122.

Dumlu, A., Varol, A., Yalçınkaya, Ş., Özbayrak, S. (2011). Oral ve intravenöz bifosfonat kaynaklı çene osteonekrozu. Türkiye Klinikleri J Dental Sci, 17, 70-75.

Elloumi, J., Jellali, K., Jemel, I., Aifa, S. (2012). Monoclonal antibodies as cancer therapeutics. Recent Pat Biotechnol, 6, 45-56.

Erdoğan, M. A. (2019). Cancer, drug targeting and targeted therapies. Asian Journal of Emerging Research, $1(2), 69-81$.

Eskiizmir, G., Ermertcan, A. T., Yapici, K. (2017). Nanomaterials: promising structures for the management of oral cancer. 1st Ed., Andronescu E, Grumezesc A. (Eds), Nanostructures for Oral Medicine, Elsevier, Philadelphia, United States, pp. 511-544.

Fizazi, K., Sternberg, C. N., Fitzpatrick, J. M., Watson, R. W., Tabesh, M. (2010). Role of targeted therapy in the treatment of advanced prostate cancer. BJU Int, 105, 748-767.

Font, R. G., García, M. L., Martínez, J. M. (2008). Osteochemonecrosis of the jaws due to bisphosphonate treatment. Update. Med Oral Patol Oral Cir Bucal, 13, E318-24.

Fukumura, D., Jain, R. K. (2007). Tumor microvasculature and microenvironment: targets for antiangiogenesis and normalization. Microvasc Res, 74, 72.

Greish, K. (2007). Enhanced permeability and retention of macromolecular drugs in solid tumors: a royal gate for targeted anticancer nanomedicines. J Drug Target, 15, 457.

Hamid, O. (2004). Emerging treatments in oncology: focus on tyrosine kinase (erbB) receptor inhibitors. J Am Pharm Assoc, 44, 52-58

Harris, A. L. (2002). Hypoxia- a key regulatory factor in tumour growth, Nat Rev Cancer, 2, 38. 
Hashizume, H., Baluk, P., Morikawa, S., McLean, J. W., Thurston, G., Roberge, S., Jain, R. K., McDonald, D. M. (2000). Openings between defective endothelial cells explain tumor vessel leakiness. Am J Pathol, 156, 1363.

Henry, D., von Moos R., Vadhan-Raj, S., Hungria, V., Spencer, A., Hirsh, V., Wang, J., Jun, S., Yeh, H., Dansey, R. (2009). A double blind randomized study of denosumab versus zoledronic acid for the treatment of bone metastasis in patients with advanced cancer. Eur J Cancer, 7(suppl), 11.

Hodi, F. S., O'Day, S. J., McDermott, D. F., et al. (2010). Improved survival with ipilimumab in patients with metastatic melanoma. N Engl J Med, 363, 711-723.

Hurwitz, H., Fehrenbacher, L., Novotny, W., Cartwright, T., Hainsworth, J., Heim, W., Berlin, J., Baron, A., Griffing, S., Holmgren, E., Ferrara, N., Fyfe, G., Rogers, B., Ross, R., Kabbinavar, F. (2004). Bevacizumab plus irinotecan, fluorouracil, and leucovorin for metastatic colorectal cancer. N Engl J Med, 350, 2335-2342.

Jain, R. K. (2003). Molecular regulation of vessel maturation, Nat Med, 9, 685.

Kaş, H. S., Eldem, T. (2002). Kontrollü salım sistemlerinin hedeflendirilmesi. Gürsoy, A. (Editor), Kontrollü salım sistemleri, Kontrollü Salım Sistemleri Derneği Yayını, İstanbul, pp. 308.

Keating, M. J., Cazin, B., Coutre, S., Birhiray, R., Kovacsovics, T., Langer, W., Leber, B., Maughan, T., Rai, K., Tjønnfjord, G., Bekradda, M., Itzhaki, M., Hérait, P. (2002). Campath-1H treatment of T-cell prolymphocytic leukemia in patients for whom at least one prior chemotherapy regimen has failed. J Clin Oncol, 20, 205-213.

Khan, A. A., Morrison, A., Hanley, D. A., et al. (2015). Diagnosis and management of osteonecrosis of the jaw: a systematic review and international consensus. J Bone Miner Res, 30, 3-23.

Khan, A. A., Morrison, A., Kendler, D. L., et al. (2017). Case-based review of osteonecrosis of the jaw (ONJ) and application of the international recommendations for management from the international task force on ONJ. J Clin Densitom, 20, 8-24.

Kopecek, J., Kopeckova, P., Minko, T., Lu, Z. R., Peterson, C. M. (2001). Water soluble polymers in tumor targeted delivery, J Control Release, 74, 147.

Kraft, A., Weindel, K., Ochs, A., Marth, C., Zmija, J., Schumacher, P., Unger, C., Marmé, D., Gastl, G. (1999). Vascular endothelial growth factor in the sera and effusions of patients with malignant and nonmalignant disease. Cancer, 85, 178-187.

Lammers, T., Hennink, W. E., Storm, G. (2008). Tumour targeted nanomedicines: principles and practice, Brit J Cancer, 99, 392.

Leaf, C. (2004). Why we are losing the war on cancer (and how to win it), Fortune, 149, 84.

Los, M., Roodhart, J. M., Voest, E. E. (2007). Target practice: lessons from phase III trials with bevacizumab and vatalanib in the treatment of advanced colorectal cancer. The Oncologist, 12, 443-450.

Macfarlane, R. J., Chi, K. N. (2010). Nover targeted therapies for prostate cancer. Urol Clin N Am, 37, 105-119. 
Maloney, D. G., Grillo-López, A. J., White, C. A., Bodkin, D., Schilder, R. J., Neidhart, J. A., Janakiraman, N., Foon, K. A., Liles, T. M., Dallaire, B. K., Wey, K., Royston, I., Davis, T., Levy, R. (1997). IDEC-C2B8 (Rituximab) anti-CD20 monoclonal antibody therapy in patients with relapsed low-grade non-Hodgkin's lymphoma. Blood, 90, 2188-2195.

Marx, R. E. (2003). Pamidronate (Aredia) and zoledronate (Zometa) induced avascular necrosis of the jaws: a growing epidemic. J Oral Maxillofac Surg, 61, 1115-1117.

Marx, R. E. (2011). Oral and intravenous bisphosphonate-induced osteonecrosis of the jaws: history, etiology, prevention, and treatment. 2nd edition, Quintessence.

Matsumura, Y., Maeda, H. (1986). A new concept for macromolecular therapeutics in cancer chemotherapy: mechanism of tumoritropic accumulation of proteins and the antitumor agent smancs. Cancer Res, 46, 6387.

Nicolatou-Galitis, O., Schiødt, M., Mendes, R.A., Ripamonti, C., Hope, S., Drudge-Coates, L., Niepel, D., Van den Wyngaert, T. (2019). Medication-related osteonecrosis of the jaw: definition and best practice for prevention, diagnosis, and treatment. Oral Surg Oral Med Oral Pathol Oral Radiol, 127,117-135.

Özbayrak, S., Pekiner, F. (2016). Ağız kanserleri, erken tanı bakımından diş hekimliği, Quintessence Yayıncilık, İstanbul.

Özbayrak, S. (2017). Oral mukoza ve hastalıkları. 3. Baskı, Quintessence Yayıncılık, İstanbul.

Pekiner, F. N. (2014). Bifosfonatlara bağlı olarak gelişen osteonekroz. Dental Klinik Dergisi, 8, 30-35.

Piccaluga, P. P., Agostinelli, C., Righi, S., Zinzani, P. L., Pileri, S. A. (2007). Expression of CD52 in peripheral T-cell lymphoma. Haematologica, 92, 566-567.

Press, M. F., Pike, M. C., Chazin, V. R., Hung, G., Udove, J. A., Markowicz, M., Danyluk, J., Godolphin, W., Sliwkowski, M., Akita, R., et al. (1993). HER-2/neu expression in nodenegative breast cancer: direct tissue quantitation by computerized image analysis and association of overexpression with increased risk of recurrent disease. Cancer Res, 53, 4960-4970.

Ratzinger, G., Reagan, J. L., Heller, G., Busam, K. J., Young, J. W. (2003). Differential CD52 expression by distinct myeloid dendritic cell subsets: implications for alemtuzumab activity at the level of antigen presentation in allogeneic graft-host interactions in transplantation. Blood, 101, 1422- 1429.

Ravdin, P. M., Chamness, G. C. (1995). The c-erbB-2 proto-oncogene as a prognostic and predictive marker in breast cancer: a paradigm aborat development of other macromolecular markers-a review. Gene, 159, 19-27.

Reff, M. E., Carner, K., Chambers, K. S., Chinn, P. C., Leonard, J. E., Raab, R., Newman, R. A., Hanna, N., Anderson, D. R. (1994). Depletion of B cells in vivo by a chimeric mouse human monoclonal antibody to CD20. Blood, 83, 435-445. 
Riechmann, L., Clark, M., Waldmann, H., Winter, G. (1988). Reshaping human antibodies for therapy. Nature, 332, 323-327.

Rosella, D., Papi, P., Giardino, R., Cicalini, E., Piccoli, L., Pompa, G. (2016). Medication-related osteonecrosis of the jaw: clinical and practical guidelines. J Int Soc Prevent Communit Dent 6,97-104.

Ruggiero, S. L., Dodson, T. B., Fantasia, J., Goodday, R., Aghaloo, T., Mehrotra, B., O’Ryan, F. (2014). American association of oral and maxillofacial surgeons position paper on medication-related osteonecrosis of the jaw-2014 update. J Oral Maxillofac Surg, 72, 1938-1956.

Seshadri, R., Firgaira, F. A., Horsfall, D. J., McCaul, K., Setlur, V., Kitchen, P. (1993). Clinical significance of HER-2/neu oncogene amplification in primary breast cancer. J Clin Oncol, 11, 1936-1942.

Slamon, D. J., Leyland-Jones, B., Shak, S., Fuchs, H., Paton, V., Bajamonde, A., Fleming, T., Eiermann, W., Wolter, J., Pegram, M., Baselga, J., Norton, L. (2001). Use of chemotherapy plus a monoclonal antibody against HER2 for metastatic breast cancer that overexpresses HER2. N Engl J Med, 344, 783-792.

Şakalar, Ç., İzgi, K., Canatan, H. (2013). Kanser immün terapi ve monoklonal antikorlar. F.Ü. Sağ Bil Tıp Derg, 27(2), 105-110.

Tatum, J. L., Kelloff, G. J., Gillies, R. J., Arbeit, J. M., Brown, J. M., Chao, K. S., Chapman, J. D., Eckelman, W. C., Fyles, A. W., Giaccia, A. J., Hill, R. P., Koch, C. J., Krishna, M. C., Krohn, K. A. (2006). Hypoxia: importance in tumor biology, noninvasive measurement by imaging, and value of its measurement in the management of cancer therapy. Int J Radiat Biol, 82, 699.

Taylor, K. H., Middlefell, L. S., Mizen, K. D. (2010). Osteonecrosis of the jaws induced by anti-RANK ligand therapy. Br J Oral Maxillofac Surg, 48, 221-223.

Waldmann, T. A. (2003). Immunotherapy: past, present and future. Nature Medicine, 9, 269-277.

Wu, J., Akaike, T., Maeda, H. (1998). Modulation of enhanced vascular permeability in tumors by a bradykinin antagonist, a cyclooxygenase inhibitor, and a nitric oxide scavenger. Cancer Res, 58.

Yoneda, T., Hagino, H., Sugimoto, T., Ohta, H., Takahashi, S., Soen, S., Taguchi, A., Nagata, T., Urade, M., Shibahara, T., Toyosawa, S. (2017). J Bone Miner Metab, 35, 6-19.

Yuan, F., Dellian, M., Fukumura, D., Leunig, M., Berk, D. A., Torchilin, V. P., Jain, R. K. (1995). Vascular permeability in a human tumor xenograft: molecular size dependence and cutoff size. Cancer Res, 55, 3752. 